\title{
Asian American Medicare Beneficiaries Disproportionately Receive Invasive Mechanical Ventilation When Hospitalized at the End-of-Life
}

\author{
Zhimeng Jia, $M D^{7}{ }^{1}$, Richard E. Leiter, $M D, M A^{1,2,3}$, Justin J. Sanders, $M D, M S c^{1,2,3,4}$, \\ Donald R. Sullivan, $M D, M A, M C R^{5,6}$, Pedro Gozalo, $P h D^{7}$, Jennifer N. Bunker, $M P H^{8}$, and \\ Joan M. Teno, MD, $M S^{8}$
}

\begin{abstract}
'Department of Psychosocial Oncology and Palliative Care, Dana-Farber Cancer Institute, Boston, MA, USA; ${ }^{2}$ Division of Palliative Medicine, Department of Medicine, Brigham and Women's Hospital, Boston, MA, USA; ${ }^{3}$ Harvard Medical School, Boston, MA, USA; ${ }^{4}$ Ariadne Labs, Boston, MA, USA; ${ }^{5}$ Division of Pulmonary and Critical Care Medicine, Department of Medicine, Oregon Health \& Science University (OHSU), Portland, OR, USA; ${ }^{6}$ Center to Improve Veteran Involvement in Care, Veterans Affairs Portland Healthcare System, Portland, OR, USA; ${ }^{7}$ Department of Health Services, Policy \& Practice, Brown University School of Public Health, Providence, RI, USA; ${ }^{8}$ Division of General Internal Medicine and Geriatrics, School of Medicine, Health \& Science University, Portland, OR, USA.
\end{abstract}

BACKGROUND: Asian Americans are the fastest-growing ethnic minority in the USA, but we know little about the end-of-life care for this population.

OBJECTIVE: Compare invasive mechanical ventilation (IMV) use between older Asian and White decedents with hospitalization in the last 30 days of life.

DESIGN: Population-based retrospective cohort study. PARTICIPANTS: A 20\% random sample of 2000-2017 Medicare fee-for-service decedents who were 66 years or older and had a hospitalization in the last 30 days of life. EXPOSURE: White and Asian ethnicity as collected by the Social Security Administration.

MAIN MEASURES: We identified IMV using validated procedural codes. We compared IMV use between Asian and White fee-for-service decedents using random-effects logistic regression analysis, adjusting for sociodemographics, admitting diagnosis, comorbidities, and secular trends.

KEY RESULTS: From 2000 to 2017, we identified 2.1 million White $(54.5 \%$ female, $82.4 \pm 8.1$ mean age) and 28,328 Asian (50.8\% female, 82.6 \pm 8.1 mean age) Medicare fee-for-service decedents hospitalized in the last 30 days. Compared to White decedents, Asian fee-for-service decedents have an increased adjusted odds ratio (AOR) of 1.42 (95\%CI: 1.38-1.47) for IMV. In sub-analyses, Asians' AOR for IMV differed by admitting diagnoses (cancer AOR=1.32, 95\%CI: 1.15-1.51; congestive heart failure $\mathrm{AOR}=1.75,95 \% \mathrm{CI}: 1.47-2.08$; dementia $\mathrm{AOR}=1.93$, 95\%CI: 1.70-2.20; and chronic obstructive pulmonary disease AOR=2.25, 95\%CI: 1.76-2.89).

CONCLUSIONS: Compared to White decedents, Asian Medicare decedents are more likely to receive IMV when hospitalized at the end-of-life, especially among patients with non-cancer admitting diagnoses. Future research to

Prior presentations The major findings of this study were presented at the University of Colorado Virtual Palliative Care Research Day and the Chinese American Medical Society Annual Scientific Conference on October 20, 2020, and November 8, 2020, respectively.

Received December 9, 2020

Accepted April 1, 2021

Published online April 26, 2021 better understand the reasons for these differences and perceived quality of end-of-life care among Asian Americans is urgently needed.

KEY WORDS: end-of-life; Asian; ventilation; disparities; geriatric.

J Gen Intern Med 37(4):737-44

DOI: $10.1007 / \mathrm{s} 11606-021-06794-6$

(C) Society of General Internal Medicine 2021

\section{INTRODUCTION}

The Asian American population numbers approximately 20 million and represents the fastest-growing ethnic minority in the United States (US). ${ }^{1}$ Accompanying this rapid growth is the increasing number of Asian individuals facing serious illness and receiving end-of-life (EOL) care. ${ }^{2}$ Although EOL disparities are evident for all racial and ethnic minorities, ${ }^{3,4}$ most efforts to understand and alleviate these disparities have focused on African American and Hispanic communities. ${ }^{5-12}$ As a result, there remains a paucity of literature on $\mathrm{EOL}$ experiences of Asian Americans.

The limited evidence describing Asian Americans' EOL care reveals differences when compared with White Americans. In the last months of life, research demonstrates that Asian Americans are less likely to use hospice, more likely to be admitted to the intensive care unit (ICU), and more likely to die in hospital. ${ }^{13-19}$ However, the generalizability and applicability of these study findings may be limited by geographic restraints, ${ }^{15,19}$ temporal scope, ${ }^{13,16,17}$ and disease type. ${ }^{14,18}$ Furthermore, it is unclear how national policies (e.g., Patient Self-Determination Act) and the growing palliative care presence may have impacted these EOL differences. ${ }^{21}$ As a result, there is a pressing need to appraise the progression and current state of medical care for Asian Americans at the EOL.

Among medical interventions used at the EOL, invasive mechanical ventilation (IMV) holds a controversial role. Despite its life-saving potential in the setting of acute respiratory 
failure, ${ }^{25}$ its use in the setting of serious illness is associated with increased healthcare costs, ${ }^{26}$ delirium, ${ }^{27}$ in-hospital death ${ }^{26}$ and difficult decisions to withdraw life-sustaining intervention. ${ }^{28}$ Furthermore, emerging evidence suggests that high intensity, life-sustaining treatment at the EOL may be discordant with the wishes of Asian Americans. ${ }^{22-24}$ Given the potentially burdensome nature of IMV at the EOL, we sought to investigate the differences in IMV use between Asian and White Medicare beneficiaries. Specifically, we aim to (a) compare IMV use between Asian and White Medicare beneficiaries hospitalized in the last 30 days of life, (b) compare IMV use between Asian and White Medicare beneficiaries across select admitting diagnoses, and (c) explore differences in EOL care (i.e., in-hospital death, hospice enrollment, and health care transitions) between Asian Americans and White Medicare decedents.

\section{METHODOLOGY}

\section{Data and Study Population}

We conducted a retrospective cohort analysis of Medicare feefor-service beneficiaries aged $\geq 66$ years who had a hospital admission in the last 30 days of life. The Medicare fee-forservice cohort represented a $20 \%$ random sample of Medicare Parts A and B beneficiaries who died between 2000 and 2017. Due to the increasing enrollment of beneficiaries in Medicare Advantage plans, we also identified a $20 \%$ random sample of Medicare Advantage decedents from 2011 to 2017 for sensitivity analysis. ${ }^{29}$ Within each of these two cohorts, we identified four sub-cohorts based on primary admitting diagnosis using International Classification of Diseases, Ninth (ICD-9-CM) and Tenth Revisions (ICD-10-CM) codes. ${ }^{30}$ Whereas we identified congestive heart failure (CHF), chronic obstructive pulmonary disease (COPD), and cancer based on primary admitting diagnosis, we identified dementia based on the primary or first nine secondary admission diagnosis codes. Consistent with prior literature, we excluded patients with an admitting diagnosis of cardiac arrest, evidence of pre-existing tracheostomy, a death date between October 1, 2015, and December 31, 2015, and those who were hospitalized in institutions with less than five beneficiary hospitalizations per year. ${ }^{30}$ The Institutional Review Boards of Oregon Health and Science University and Brown University approved this study and waived patient consent requirements.

\section{Measures}

We used validated ICD-9/10CM procedure codes (96.7x/ 5A1935Z,5A1945Z,5A1955Z) to identify IMV use among hospitalized patients in the last 30 days of life. ${ }^{31}$ We extracted socio-demographic characteristics from the Medicare Beneficiary Enrollment file which included age, race/ethnicity, sex, residence, and Medicaid-eligibility status. Race/Ethnicity data were based on voluntary, self-reported data collected by the Social Security Administration (e.g., White, Asian, etc.); ${ }^{32}$ we excluded beneficiaries with "unknown" or "other" ethnicity. We abstracted comorbidities from ICD-9/10-CM codes listed on the bill for hospitalization in the last 30 days of life. We also obtained additional EOL care measures from Medicare claims data include in-hospital death, admission to intensive care unit (ICU), hospice enrollment at death, hospice enrollment in the last 3 days of life, and healthcare transitions in the last 3 days of life. Finally, we obtained hospital-level characteristics (e.g., hospital care intensity index ${ }^{33}$ hospital bed size, facility type, hospital deaths, ICU use) by linking the Medicare Provider Number of the hospital bills with the publicly available 2017 Dartmouth Atlas Hospital Care Intensity data. ${ }^{34}$

\section{Analysis}

We used descriptive statistics to characterize patient demographics by ethnicity and IMV use with $95 \%$ CIs calculated using Clopper-Pearson methods. We interpreted comparisons as different if their 95\% CIs did not overlap. We performed multivariable random-effects logistic regressions to compare IMV use between Asian and White fee-for-service decedents clustered by hospital and adjusting for age, sex, admitting diagnosis, and Charlson comorbidity index. ${ }^{35}$ We adjusted for secular trends by creating dichotomous year of death variables with the year 2000 as the reference point. ${ }^{30} \mathrm{We}$ also conducted subgroup analyses to investigate the association of Asian ethnicity with IMV use across admitting diagnoses (CHF, COPD, cancer, and dementia), and we tabulated EOL care measures by ethnicity for descriptive comparisons.

We performed sensitivity analyses to account for potential variations across Medicare plans. Using a cohort of Medicare Advantage decedents who died between 2011 and 2017, we conducted multivariable random-effects logistic regressions to compare IMV use between Asian and White decedents overall and across admitting diagnoses. We also captured EOL care measures for descriptive comparisons between ethnicity and with the Medicare fee-for-service data.

We conducted additional exploratory analyses to account for hospital-level variations in care. Pooling Medicare Advantage and fee-for-service decedents from 2011 to 2017, we explored both a random-effects and a fixed-effects model. The randomeffects model examined the overall or between-hospital variation in IMV use, and the fixed-effects model examined the association of Asian ethnicity and IMV within a hospital. ${ }^{36,37}$ These regression analyses adjusted for Medicaid-eligibility status in addition to sociodemographics, admitting diagnosis, comorbidities, and secular trends. Additionally, we tabulated hospital-level characteristics of the pooled decedents using chisquared, or independent sample $t$ tests, as appropriate. Data analysis was done using Stata.v15.0 (StataCorp).

\section{RESULTS}

Our Medicare sample included 2,142,329 White fee-forservice (55.1\% female; mean [SD] age, 82.4 [8.1] years), 
Table 1 Characteristics of Medicare Decedents by Plan, Race, and Reception of Invasive Mechanical Ventilation

\begin{tabular}{|c|c|c|c|c|c|c|c|c|}
\hline & \multicolumn{4}{|c|}{ Medicare fee-for-service decedents ${ }^{*}$} & \multicolumn{4}{|c|}{ Medicare advantage decedents ${ }^{\dagger}$} \\
\hline & \multicolumn{2}{|c|}{ Whites $(n=2,142,329)$} & \multicolumn{2}{|c|}{ Asians $(n=\mathbf{2 8 , 4 3 0})$} & \multicolumn{2}{|c|}{ Whites $(n=275,645)$} & \multicolumn{2}{|c|}{ Asians $(n=6,392)$} \\
\hline & $\begin{array}{l}\text { No IMV } \\
(n=1,792,215)\end{array}$ & $\begin{array}{l}\text { IMV } \\
(n=350,114)\end{array}$ & $\begin{array}{l}\text { No IMV } \\
(n=\mathbf{2 1 , 0 7 1 )}\end{array}$ & $\begin{array}{l}\text { IMV } \\
(n=7359)\end{array}$ & $\begin{array}{l}\text { No IMV } \\
(n=\mathbf{2 2 0 , 7 7 2 )}\end{array}$ & $\begin{array}{l}\text { IMV } \\
(n=54,873)\end{array}$ & $\begin{array}{l}\text { No IMV } \\
(n=4,599)\end{array}$ & $\begin{array}{l}\text { IMV } \\
(n=1,793)\end{array}$ \\
\hline Age, mean (SD) & $83.0(8.1)$ & $79.5(7.5)$ & $83.3(8.2)$ & $80.7(7.7)$ & $82.5(8.2)$ & $78.6(7.4)$ & $83.9(8.6)$ & $80.2(7.9)$ \\
\hline $\begin{array}{l}\text { Female, } \% \\
(95 \% \mathrm{CI})\end{array}$ & $55.4(55.3-55.4)$ & $\begin{array}{l}50.2(50.0- \\
50.3)\end{array}$ & $\begin{array}{l}51.6(50.9- \\
52.3)\end{array}$ & $\begin{array}{l}48.5 \\
(47.4 \\
49.7)\end{array}$ & $\begin{array}{l}53.1(52.9- \\
53.3)\end{array}$ & $\begin{array}{l}48.6(48.2- \\
49.0)\end{array}$ & $\begin{array}{l}50.4(48.9 \\
51.8)\end{array}$ & $\begin{array}{l}44.8(42.5- \\
47.1)\end{array}$ \\
\hline \multicolumn{9}{|c|}{ Admitting diagnosis, \% (95\%CI) } \\
\hline $\begin{array}{l}\text { Pneumonia/ } \\
\text { sepsis }\end{array}$ & $19.7(19.6-19.8)$ & $\begin{array}{l}26.9(25.9- \\
26.2)\end{array}$ & $\begin{array}{l}26.5(25.9- \\
27.1)\end{array}$ & $\begin{array}{l}34.4 \\
(33.3- \\
35.5)\end{array}$ & $\begin{array}{l}20.3(20.2- \\
20.5)\end{array}$ & $\begin{array}{l}31.2(30.8- \\
31.6)\end{array}$ & $\begin{array}{l}26.5(25.2- \\
27.8)\end{array}$ & $\begin{array}{l}36.6(34.4 \\
38.9)\end{array}$ \\
\hline Cancer & $10.7(10.7-10.8)$ & $3.9(3.9-4.0)$ & $\begin{array}{l}12.5(12.1- \\
13.0)\end{array}$ & $\begin{array}{l}3.5(3.1- \\
3.9)\end{array}$ & $\begin{array}{l}10.0(9.9- \\
10.1)\end{array}$ & $\begin{array}{l}3.5(3.3- \\
3.6)\end{array}$ & $\begin{array}{l}11.2(10.3- \\
12.2)\end{array}$ & $\begin{array}{l}3.2(2.5- \\
4.2)\end{array}$ \\
\hline $\mathrm{CHF}$ & $7.1(7.0-7.1)$ & $3.5(3.4-3.6)$ & $4.9(4.6-5.2)$ & $\begin{array}{l}2.4(2.0- \\
2.8)\end{array}$ & $6.7(6.6-6.9)$ & $\begin{array}{l}2.6(2.5- \\
2.7)\end{array}$ & $\begin{array}{l}4.9(4.3- \\
5.6)\end{array}$ & $\begin{array}{l}2.2(1.6- \\
3.0)\end{array}$ \\
\hline COPD & $2.2(2.1-2.2)$ & $2.0(2.0-2.1)$ & $1.3(1.1-1.4)$ & $\begin{array}{l}1.4(1.1- \\
1.7)\end{array}$ & $1.9(1.8-1.9)$ & $\begin{array}{l}1.5(1.4- \\
1.6)\end{array}$ & $\begin{array}{l}0.8(0.6- \\
1.2)\end{array}$ & $\begin{array}{l}1.3(0.8- \\
1.9)\end{array}$ \\
\hline Dementia ${ }^{\ddagger}$ & $13.3(13.2-13.3)$ & $4.0(3.9-4.1)$ & $\begin{array}{l}11.8(11.4- \\
12.3)\end{array}$ & $\begin{array}{l}4.4(3.9- \\
4.9)\end{array}$ & $\begin{array}{l}18.5(18.4- \\
18.7)\end{array}$ & $\begin{array}{l}5.2(5.1- \\
5.4)\end{array}$ & $\begin{array}{l}18.9(17.7- \\
20.0)\end{array}$ & $\begin{array}{l}5.7(4.6- \\
6.9)\end{array}$ \\
\hline $\begin{array}{l}\text { Charlson, mean } \\
\text { (SD) }\end{array}$ & $2.9(2.6)$ & $2.4(2.2)$ & $3.3(2.8)$ & $2.7(2.4)$ & $3.9(2.9)$ & $3.4(2.5)$ & $4.2(3.0)$ & $3.5(2.7)$ \\
\hline $\begin{array}{l}\text { Medicaid- } \\
\text { eligibility, \% } \\
\text { (95\%CI) }\end{array}$ & $\begin{array}{l}18.8(18.8- \\
18.9)^{\S}\end{array}$ & $\begin{array}{l}16.1(15.9- \\
16.2)^{\S}\end{array}$ & $\begin{array}{l}32.6(31.9- \\
33.4)^{\S}\end{array}$ & $\begin{array}{l}34.4 \\
(33.1- \\
35.7)^{\S}\end{array}$ & $\begin{array}{l}17.1(17.0- \\
17.3)\end{array}$ & $\begin{array}{l}15.9(15.6- \\
16.2)\end{array}$ & $\begin{array}{l}27.2(25.9- \\
28.5)\end{array}$ & $\begin{array}{l}29.6(27.5- \\
31.8)\end{array}$ \\
\hline
\end{tabular}

*Based on a $20 \%$ random sample of 2000-2017 Medicare fee-for-Service beneficiaries

${ }^{*}$ Based on a $20 \%$ sample of 2011-2017 Medicare Advantage beneficiaries

${ }^{7}$ Dementia diagnosis is identified based on primary or first nine secondary diagnosis codes

${ }^{\S}$ Medicaid-eligibility proportions for Medicare fee-for-service beneficiaries are calculated using 2006-2017 data

Abbreviations: $C H F$, congestive heart failure; COPD, chronic obstructive lung disease; CI, confidence interval; SD, standard deviation

28,430 Asian fee-for-service (50.8\% female; mean [SD] age 82.6 [8.1] years), 275,645 White Advantage (52.2\% female; mean [SD] age, 81.8 [8.2] years), and 6,392 Asian Advantage (48.8\% female; mean [SD] age, 82.9 [8.5] years) decedents who were hospitalized in the last 30 days of life (Table 1). Pneumonia/sepsis represented the leading cause of admission for all cohorts, followed by cancer, congestive heart failure (CHF), and chronic obstructive pulmonary disease (COPD). Charlson comorbidity scores did not differ significantly between cohorts. However, Asian decedents enrolled in both Medicare fee-for-service and Advantage plans had a larger proportion of Medicaid-eligible beneficiaries compared to White decedents (Table 1).

\section{Comparison of IMV Use between Asian and White Medicare Fee-for-Service Decedents}

Overall, $16.3 \%$ of White and $25.9 \%$ of Asian Medicare fee-for-service decedents received IMV, a $9.6 \%$ absolute difference (Table 1). From 2000 to 2017, the proportion of IMV use increased for both White fee-for-service (\% receipt $=14.7 \%$ vs $19.2 \%)$ and Asian fee-for-service (\% receipt $=25.0 \%$ vs $26.5 \%$ ) decedents (Fig. 1). Compared to Whites, Asian fee-for-service decedents had an increased adjusted odds ratio (AOR) of $1.42(95 \% \mathrm{CI}$ : 1.38-1.47) for IMV. In sub-analyses, Asians' AOR for IMV trend higher for non-cancer diagnoses (congestive heart failure $\mathrm{AOR}=1.75,95 \% \mathrm{CI}: 1.47-2.08$; dementia $\mathrm{AOR}=1.93,95 \% \mathrm{CI}: 1.70-2.20$; and chronic obstructive pulmonary disease $\mathrm{AOR}=2.25,95 \% \mathrm{CI}: 1.76-2.89)$ than cancer $(\mathrm{AOR}=1.32,95 \% \mathrm{CI}: 1.15-1.51)$ (Fig. 2).

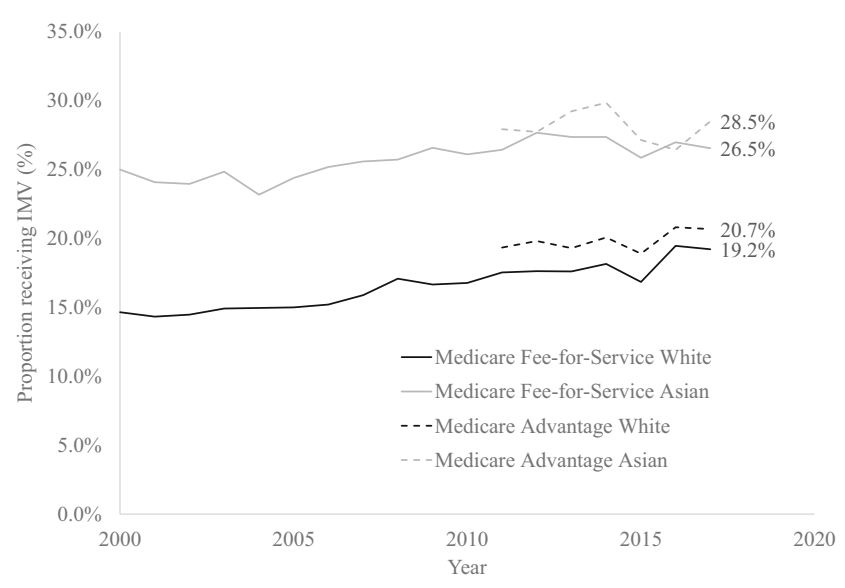

Figure 1 IMV use at the end of life for hospitalized Asian and White Medicare fee-for-service from 2000 to 2017 and MA decedents from 2011 to 2017. Overall, 16.3\% of White fee-for-service (solid black line), $25.9 \%$ of Asian fee-for-service (dashed black line), $\mathbf{1 9 . 9 \%}$ White Medicare Advantage (solid grey line), and 28.1\% Asian Medicare Advantage (dashed grey line) decedents received IMV. There was an increase in the proportion of White fee-for-service (15.2 to 19.2\%), Asian fee-for-service (25.0 to $26.5 \%$ ), White Medicare Advantage (19.3 to 20.7\%), and Asian Medicare Advantage (27.9 to $28.5 \%$ ) decedents receiving IMV from 2000 to 2017. Abbreviations: IMV, invasive mechanical ventilation. 


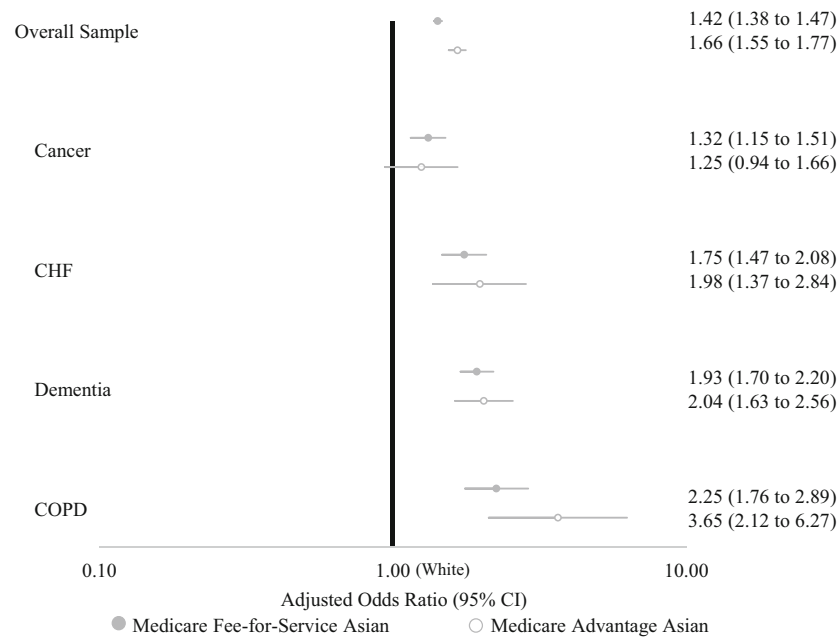

Figure 2 Forest plot showing the adjusted odds ratio of hospitalized Asian Medicare Advantage and Fee-for-Service beneficiaries for

IMV at the EOL, by admitting diagnosis and Medicare plan. Comparison to White beneficiaries is denoted by the black vertical line corresponding to an adjusted odds ratio of 1.00. Each odds ratio is derived from a random-effects logistic regression model adjusting for age, sex, admitting diagnosis, comorbidities, and secular trends. Adjusted odds ratio for Medicare Advantage decedents also accounted for Medicaid-eligibility. Abbreviations: IMV, invasive mechanical ventilation; EOL, end-of-life; and CI, confidence interval.

\section{Comparisons of End-of-Life Care between Asian and White Medicare Fee-for-Service Decedents}

Compared to White decedents, Asian fee-for-service decedents had higher rates of in-hospital deaths $(62.1 \%, 95 \% \mathrm{CI}$ : 61.6-62.7 vs $51.4 \%, 95 \% \mathrm{CI}$ : $51.3-51.4)$, intensive care unit admission $(52.7 \%$, 95\%CI: $52.1-53.2$ vs $40.1 \%, 95 \% \mathrm{CI}$ : 40.0-40.2), lower rates of hospice enrollment (22.5\%, 95\%CI: $22.0-23.0$ vs $31.6 \%$, 95\%CI: $31.6-31.7$ ), and hospice enrollment in the last 3 days of life (8.9\%, 95\%CI: 8.6-9.3 vs 13.4\%, 95\%CI: 13.3-13.4). Among decedents who survived their hospitalization, Asian and White decedents had similar rates of health care transitions in the last three days of life (36.9\%, 95\%CI: $36.0-37.8$ vs $35.8 \%$, 95\%CI: $35.8-36.0$ ) (Fig. 3).

\section{Sensitivity Analysis Involving Medicare Advantage and Fee-for-Service Decedents from 2011 to 2017}

Overall, sensitivity analyses using Medicare Advantage data did not reveal significant changes in the direction of effects. Similar to fee-for-service decedents, Asian Medicare Advantage decedents had consistently higher rates of IMV from 2011 to 2017 (Fig. 1). Compared to White decedents, Asian Medicare Advantage decedents had higher AOR (1.66, 95\%CI: 1.55-1.77) for IMV. Furthermore, Asian Medicare Advantage decedents' AORs for IMV were higher for noncancer diagnoses than for cancer (Fig. 2). In terms of EOL measures, Asian Medicare Advantage decedents had higher rates of death in hospital $(53.6 \%$, 95\%CI: $52.3-54.8$ vs $43.0 \%$,
95\%CI: 42.8-43.2), higher ICU admission (58.5\%, 95\%CI: $57.3-59.8$ vs $56.8 \%$, 95\%CI: 56.7-57.0), lower hospice enrollment at death $(32.3 \%, 95 \% \mathrm{CI}: 31.1-33.5$ vs $44.6 \%$, 95\%CI: 44.4-44.8), and lower hospice enrollment in the last 3 days of life $(12.2 \%, 95 \%$ CI:11.4-13.0 vs $19.3 \%$, 95\%CI: 19.2-19.5) when compared with White decedents (Fig. 3). Different than fee-for-service decedents, however, Asian Medicare Advantage decedents had lower rates of healthcare transitions in the last 3 days compared to White decedents (41.0\%, 95\%CI: $39.8-42.2$ vs $45.6 \%, 95 \%$ CI: $45.4-45.8)$ (Fig. 3).

\section{Exploratory Analyses with Pooled Medicare Advantage and Fee-for-Service Decedents from 2011 to 2017}

In pooled analyses, Asian decedents had a higher likelihood of receiving IMV than White decedents in both the randomeffects (between-hospital) model (AOR=1.55, 95\%CI: 1.49 1.61) and fixed-effects (within-hospital) model (AOR $=1.51$, 95\%CI: $1.45-157)$. Nearly one-fifth $(\rho=17.7 \%, 95 \%$ CI: $16.8-$ $18.7 \%$ ) of the variance for IMV use in the random-effects model were attributed to care variations across hospitals. An exploratory analysis of the hospitals attended by patients in 2017 revealed that Asian beneficiaries were more likely than White beneficiaries to receive their EOL inpatient care in the state of California, academic teaching hospitals, and be enrolled in integrated health care systems (Table 2). Furthermore, the hospitals attended by Asian beneficiaries had higher Dartmouth Atlas hospital care intensity scores, more inpatient beds, more in-hospital deaths, and more in-hospital deaths preceded by an ICU stay (Table 2 ).

\section{DISCUSSION}

Achieving equitable and high-quality EOL care for racial and ethnic minorities represents a national objective of the US healthcare system. ${ }^{38}$ Despite prior evidence demonstrating that ethnic minorities experience disparate care at the EOL, ${ }^{3}$ little is known about the care Asian Americans receive. Our findings demonstrate that older Asian Americans disproportionately experience high-intensity care when hospitalized at the EOL. Specifically, when compared to White beneficiaries, Asian Medicare beneficiaries hospitalized at the EOL are more likely to receive IMV and have higher rates of ICU admissions, in-hospital deaths, and lower rates of hospice use. Confidence in these results is bolstered by the consistency of our findings across diagnoses, Medicare plans, and adjustment for within- and between-hospital effects. Although our findings likely raise more questions than answers, the striking differences in care suggest that older Asian adults may disproportionately receive burdensome care when hospitalized in the last month of life.

Our findings are consistent with and extend results from prior reports by offering a population-level perspective that 


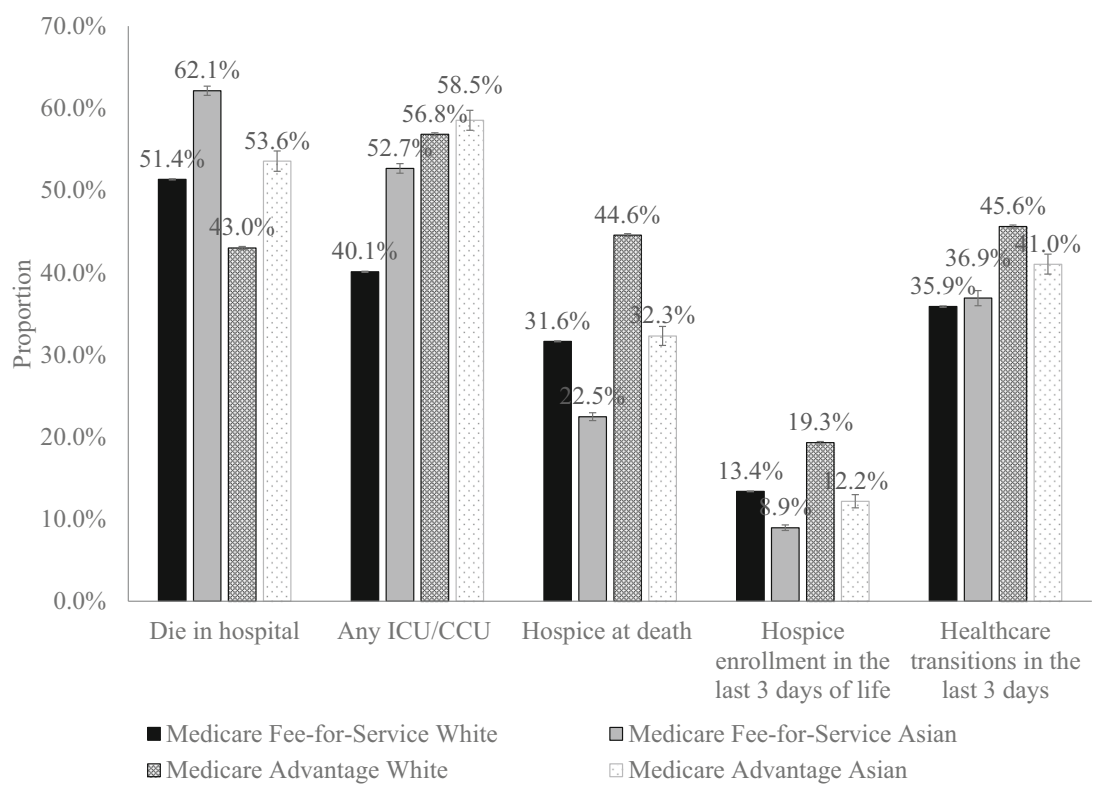

Figure 3 Among White and Asian decedents hospitalized at the EOL, in-hospital death, ICU/CCU admission, hospice use, and healthcare transitions in the last 3 days by Medicare plan. Abbreviations: EOL, end-of-life; ICU, intensive care unit; and CCU, cardiac care unit.

accounts for relevant sociodemographics, secular trends, admitting diagnoses, and hospital-level variations in care. The findings that hospitalized Asian Medicare beneficiaries have a higher likelihood of IMV use both within a hospital (i.e., fixed-effects model) and between hospitals (i.e., randomeffects model) suggest that the observed EOL differences likely extend beyond individual preferences to social, institutional, and systemic factors. ${ }^{39}$

At the individual and social level, the increased IMV use may reflect Asian patients' and caregivers' attitudes toward serious illness care. Existing literature reveals mixed attitudes of older Asian patients toward life-sustaining treatments, ${ }^{24,40-}$ 42 which appear to be influenced by acculturation, religious affiliation, and traditional Asian philosophies. ${ }^{43}$ These mixed attitudes contrast with our findings that the hospitals attended by older Asian patients exhibit higher care intensity metrics. A possible explanation may be that Asian Americans are geographically restricted from accessing institutions that provides lower intensity of care at the end-of-life. Another explanation may be that the observed differences reflect the preferences and influence of family caregivers. While family is consistently endorsed as a key player in EOL decisionmaking among Asian Americans, ${ }^{44} 49$ intergenerational differences in acculturation level complicate our understanding of familial roles at the EOL. ${ }^{50}$ Future research into the mechanism by which Asian families make EOL decisions will enable the delivery of family-centered, goal-concordant, and culturally tailored EOL care.

At the institutional level, we found that Asian Medicare beneficiaries, who are hospitalized at the EOL, are more likely to receive high-intensity care both within and across hospital settings. This pattern of healthcare utilization may relate to differential engagement with palliative care services. ${ }^{3}$ While researchers have consistently linked palliative care with higher

Table 2 Characteristics of Hospitals that Asian and White Medicare Decedents Patronized in the Last Month of Life in 2017

\begin{tabular}{|c|c|c|c|}
\hline$\overline{\text { Characteristics (\%) }}$ & $\begin{array}{l}\text { White Medicare decedents } \\
(n=148,764)\end{array}$ & $\begin{array}{l}\text { Asian Medicare decedents } \\
(n=3182)\end{array}$ & $P$ value \\
\hline \multicolumn{4}{|l|}{ Hospital location } \\
\hline & Florida $(8.4 \%)$ & California $(43.3 \%)$ & $<0.001$ \\
\hline & California $(8.2 \%)$ & New York $(9.4 \%)$ & \\
\hline & Texas $(6.7 \%)$ & Hawaii $(7.9 \%)$ & \\
\hline & New York $(6.2 \%)$ & Texas $(5.9 \%)$ & \\
\hline & Pennsylvania $(5.6 \%)$ & Florida $(3.5 \%)$ & \\
\hline Proportion of academic teaching hospitals & $17,085(11.5 \%)$ & $527(16.6 \%)$ & $<0.001$ \\
\hline Proportion of integrated academic medical centers & $11,820(8.0 \%)$ & $404(12.9 \%)$ & $<0.001$ \\
\hline Average number of beds of hospitals patronized (SD) & $391(318)$ & $417(359)$ & $<0.001$ \\
\hline Average hospital health care intensity (SD) & $1.0(0.3)$ & $1.3(0.5)$ & $<0.001$ \\
\hline Average hospital deaths (SD) & $24.6(6.8)$ & $30.0(8.0)$ & $<0.001$ \\
\hline $\begin{array}{l}\text { Average hospital death preceded by ICU admission } \\
\text { (SD) }\end{array}$ & $18.0(5.4)$ & $23.1(7.7)$ & $<0.001$ \\
\hline Average hospice reimbursement per hospital (SD) & $56.5(10.8)$ & $49.9(11.8)$ & $<0.001$ \\
\hline
\end{tabular}

*Based on a 20\% random sample of 2017 Medicare fee-for-service and Advantage beneficiaries 
quality and lower intensity EOL care, ${ }^{51-55}$ few have investigated the impact of palliative care on Asian Americans. ${ }^{56}$ What is known is that Asian Americans continue to face many barriers in accessing palliative care services, including underreporting of symptoms, low engagement with advance care planning, low knowledge of available end-of-life services (e.g., hospice), and significant communication barriers (e.g., language discordance).$^{57}$ These barriers are reinforced by clinicians' implicit biases toward and unfamiliarity with Asian cultural nuances during EOL conversations. ${ }^{58,59}$ Thus, an examination of the pattern of use and effectiveness of palliative care among Asian Americans may be important in exposing inequities in palliative care access and engagement.

Finally, at the policy level, several forces may contribute to the sustained differences in EOL care intensity for Asian Americans. First, high rates of misclassification and aggregation of Asian Americans into "other" and "ethnic minorities" result in under-representation of Asian Americans in large databases. ${ }^{60}$ Second, reporting of Asian American data in aggregate may mask important health disparities among the diverse and heterogeneous Asian sub-populations. ${ }^{60,61}$ Third, historical discriminatory immigration policies and the Asian model minority myth (i.e., above-average achievement in education and socioeconomic status) perpetuate the stereotype of Asian Americans as the outsider. ${ }^{62,}{ }^{63}$ Together, the underrepresentation, aggregation, and alienation may have increased the difficulty and diminished societal interest in understanding health disparities Asian Americans' experience at the EOL. As periods of instability have historically resulted in scapegoating of minority groups, policymakers should be vigilant of the potential for the widening of EOL health disparities for Asian Americans during the COVID-19 pandemic.

\section{LIMITATIONS}

This is the first nationally representative cohort analysis of Asian Medicare beneficiaries' use of intensive care and hospice services when hospitalized at the EOL, yet it has limitations. First, our data should be interpreted in the context of hospitalized, older adults at the EOL. Although more than half of Medicare beneficiaries received hospitalization in the last month of life,${ }^{64}$ our findings may not generalize to younger patients and individuals who were not hospitalized in the last 30 days of life. Second, our study was unable to capture patient nor family preferences for EOL care. This limits our understanding of whether the observed differences in care were goal-concordant. Third, we were unable to account for the severity of disease at admission, acculturation level, religious affiliation, and education. This may have biased the findings away from null. Finally, as Asian Americans were evaluated as an aggregate group, it is unclear how our findings may apply to individual Asian sub-populations.

\section{CONCLUSION}

From 2000 to 2017, persistently higher rates of IMV use were observed among Asian American Medicare beneficiaries when hospitalized at the EOL. These differences in IMV use are accompanied by higher rates of other measures of potentially burdensome EOL care including ICU admission, inhospital death, and lower rates of hospice use among Asian Americans. While observed differences are partly explained by sociodemographics and hospital-level variability, they may also signal the presence of underlying health disparities. Further research is needed to understand these potential EOL care disparities by exploring patient/caregiver shared decisionmaking preferences, evaluating the availability and effectiveness of palliative care services, and dis-aggregating Asian Americans into sub-populations.

Corresponding Author: Zhimeng Jia, MD; Department of Psychosocial Oncology and Palliative Care, Dana-Farber Cancer Institute, Boston, MA, USA (e-mail: Zhimeng_jia@dfci.harvard.edu).

Author Contribution All authors contributed to the conception and design or acquisition of data. Drs. Jia and Teno contributed to analysis and interpretation of data; all authors contributed to the writing and revising of the manuscript; and all authors provided final approval of the manuscript prior to publication.

Funding The research reported in this publication was supported by award R56AG063748 from the National Institute on Aging of the National Institute of Health.

\section{Declarations:}

Conflict of Interest: The authors declare that they do not have a conflict of interest.

Data Access, Responsibility, and Analysis: Dr. Teno had full access to all the data in the study and takes responsibility for the integrity of the data and accuracy of the data analysis.

Role of Funder/Sponsor: The funding organizations had no role in the design and conduct of the study; collection, management, analysis, and interpretation of the data; preparation, review, or approval of the manuscript; nor decision to submit the manuscript for publication. The content is solely the responsibility of the authors and does not necessarily present the official views of the National Institutes of Health nor the United States Government.

Additional Information: The code-sharing document used in this study is part of the Brown University Digital Repository. https://doi. org/10.7910/DVN/3XEJKU.

\section{REFERENCES}

1. Center PR. Key facts about Asian Americans, a diverse and growing population. http://www.pewresearch.org/fact-tank/2017/09/08/keyfacts-about-asian-americans/. Published 2017b.

2. Heron M. Deaths: Leading Causes for 2017. Natl Vital Stat Rep. 2019;68(6): 1-77.

3. Johnson KS. Racial and ethnic disparities in palliative care. $J$ Palliat Med. 2013;16(11):1329-1334.

4. Mayeda DP, Ward KT. Methods for overcoming barriers in palliative care for ethnic/racial minorities: a systematic review. Palliat Support Care. 2019:1-10. 
5. Ornstein KA, Roth DL, Huang J, et al. Evaluation of Racial Disparities in Hospice Use and End-of-Life Treatment Intensity in the REGARDS Cohort. JAMA Netw Open. 2020;3(8):e2014639.

6. Rizzuto J, Aldridge MD. Racial Disparities in Hospice Outcomes: A Race or Hospice-Level Effect? J Am Geriatr Soc. 2018;66(2):407-413.

7. Makaroun LK, Teno JM, Freedman VA, Kasper JD, Gozalo P, Mor V. Late Transitions and Bereaved Family Member Perceptions of Quality of End-of-Life Care. J Am Geriatr Soc. 2018;66(9):1730-1736.

8. Khandelwal N, Curtis JR, Freedman VA, et al. How Often Is End-of-Life Care in the United States Inconsistent with Patients' Goals of Care? J Palliat Med. 2017;20(12):1400-1404.

9. Sharma RK, Cameron KA, Chmiel JS, et al. Racial/Ethnic Differences in Inpatient Palliative Care Consultation for Patients With Advanced Cancer. J Clin Oncol. 2015;33(32):3802-3808.

10. Dionne-Odom JN, Ejem DB, Wells R, et al. Effects of a Telehealth Early Palliative Care Intervention for Family Caregivers of Persons With Advanced Heart Failure: The ENABLE CHF-PC Randomized Clinical Trial. JAMA Netw Open. 2020;3(4):e202583.

11. Sudore RL, Schillinger D, Katen MT, et al. Engaging Diverse Englishand Spanish-Speaking Older Adults in Advance Care Planning: The PREPARE Randomized Clinical Trial. JAMA Intern Med. 2018;178(12):1616-1625.

12. Cross SH, Warraich HJ. Changes in the Place of Death in the United States. N Engl J Med. 2019;381(24):2369-2370.

13. Wang SY, Hsu SH, Aldridge MD, Cherlin E, Bradley E. Racial Differences in Health Care Transitions and Hospice Use at the End of Life. $J$ Palliat Med. 2019;22(6):619-627.

14. Mehanna EK, Catalano PJ, Cagney DN, et al. Hospice utilization in elderly patients with brain metastases. J Natl Cancer Inst. 2020.

15. Wang SY, Hsu SH, Huang S, Doan KC, Gross CP, Ma X. Regional Practice Patterns and Racial/Ethnic Differences in Intensity of End-ofLife Care. Health Serv Res. 2018;53(6):4291-4309.

16. Smith AK, Earle CC, McCarthy EP. Racial and ethnic differences in endof-life care in fee-for-service Medicare beneficiaries with advanced cancer. J Am Geriatr Soc. 2009;57(1): 153-158.

17. Ngo-Metzger Q, Phillips RS, McCarthy EP. Ethnic disparities in hospice use among Asian-American and Pacific Islander patients dying with cancer. J Am Geriatr Soc. 2008;56(1):139-144

18. Foley RN, Sexton DJ, Drawz P, Ishani A, Reule S. Race, Ethnicity, and End-of-Life Care in Dialysis Patients in the United States. J Am Soc Nephrol. 2018;29(9):2387-2399.

19. Lackan NA, Eschbach K, Stimpson JP, Freeman JL, Goodwin JS. Ethnic differences in in-hospital place of death among older adults in California: effects of individual and contextual characteristics and medical resource supply. Med Care. 2009;47(2):138-145.

20. Brown CE, Engelberg RA, Sharma R, et al. Race/Ethnicity, Socioeconomic Status, and Healthcare Intensity at the End of Life. J Palliat Med. 2018;21(9):1308-1316.

21. Dumanovsky T, Augustin R, Rogers M, Lettang K, Meier DE, Morrison RS. The Growth of Palliative Care in U.S. Hospitals: A Status Report. J Palliat Med. 2016;19(1):8-15.

22. A controlled trial to improve care for seriously ill hospitalized patients. The study to understand prognoses and preferences for outcomes and risks of treatments (SUPPORT). The SUPPORT Principal Investigators. JAMA. 1995;274(20): 1591-1598.

23. Wright AA, Keating NL, Ayanian JZ, et al. Family Perspectives on Aggressive Cancer Care Near the End of Life. JAMA. 2016;315(3):284292.

24. Jia Z, Stokes SC, Pan SY, Leiter RE, Lum HD, Pan CX. Heart to Heart Cards: A Novel, Culturally Tailored, Community-Based Advance Care Planning Tool for Chinese Americans. American Journal of Hospice and Palliative Medicine ${ }^{\circledR}$. 2021:1049909121989986.

25. Wunsch H, Wagner J, Herlim M, Chong DH, Kramer AA, Halpern SD ICU occupancy and mechanical ventilator use in the United States. Crit Care Med. 2013;41(12):2712-2719.

26. Wunsch H, Linde-Zwirble WT, Angus DC, Hartman ME, Milbrandt EB, Kahn JM. The epidemiology of mechanical ventilation use in the United States. Crit Care Med. 2010;38(10):1947-1953.

27. Ely EW, Inouye SK, Bernard GR, et al. Delirium in mechanically ventilated patients: validity and reliability of the confusion assessment method for the intensive care unit (CAM-ICU). JAMA. 2001;286(21):27032710 .

28. Luce JM. End-of-life decision making in the intensive care unit. Am $J$ Respir Crit Care Med. 2010;182(1):6-11.
29. Research Data Assistance Center. Medicare managed care enrollees and the Medicare utilization files. https://www.resdac.org/resconnect /articles/1142011. Accessed September 15th, 2020.

30. Sullivan DR, Kim H, Gozalo PL, Bunker J, Teno JM. Trends in Noninvasive and Invasive Mechanical Ventilation Among Medicare Beneficiaries at the End of Life. JAMA Internal Medicine. 2020.

31. Wunsch H, Kramer A, Gershengorn HB. Validation of Intensive Care and Mechanical Ventilation Codes in Medicare Data. Crit Care Med. 2017;45(7):e711-e714

32. Eicheldinger C, Bonito A. More accurate racial and ethnic codes for Medicare administrative data. Health Care Financ Rev. 2008;29(3):27-42.

33. Sheetz KH, Dimick JB, Ghaferi AA. The association between hospital care intensity and surgical outcomes in medicare patients. JAMA Surg. 2014;149(12):1254-1259.

34. Dartmouth Altas Project. The Dartmouth Atlas of Health Care. Accessed November 9th, 2020. https://www.dartmouthatlas.org/interactiveapps/hospital-care-intensity/.

35. Charlson ME, Pompei P, Ales KL, MacKenzie CR. A new method of classifying prognostic comorbidity in longitudinal studies: development and validation. J Chronic Dis. 1987;40(5):373-383.

36. Barnato AE, Berhane Z, Weissfeld LA, et al. Racial variation in end-oflife intensive care use: a race or hospital effect? Health Serv Res. 2006;41(6):2219-2237.

37. Sharma RK, Kim H, Gozalo PL, Sullivan DR, Bunker J, Teno JM. The Black and White of Invasive Mechanical Ventilation in Advanced Dementia. J Am Geriatr Soc. 2020.

38. 2018 National Healthcare Quality and Disparities Report. Content last reviewed April 2020. Agency for Healthcare Research and Quality, Rockville, MD. https://www.ahrq.gov/research/findings/nhqrdr/ nhqdr18/index.html. Accessed November 3rd, 2020. Accessed.

39. Warnecke RB, Oh A, Breen N, et al. Approaching health disparities from a population perspective: the National Institutes of Health Centers for Population Health and Health Disparities. Am $J$ Public Health. 2008;98(9): 1608-1615.

40. Blackhall LJ, Frank G, Murphy ST, Michel V, Palmer JM, Azen SP Ethnicity and attitudes towards life sustaining technology. Social Science \& Medicine. 1999;48(12):1779-1789.

41. Bito S, Matsumura S, Singer MK, Meredith LS, Fukuhara S, Wenger NS. Acculturation and end-of-life decision making: comparison of Japanese and Japanese-American focus groups. Bioethics. 2007;21(5):251-262

42. Vaughn G, Kiyasu E, McCormick WC. Advance directive preferences among subpopulations of Asian nursing home residents in the Pacific Northwest. J Am Geriatr Soc. 2000;48(5):554-557.

43. Hsiung YY, Ferrans CE. Recognizing Chinese Americans' cultural needs in making end-of-life treatment decisions. Journal of Hospice \& Palliative Nursing. 2007;9(3): 132-140.

44. Colclough YY, Young HM. Decision making at end of life among Japanese American families. J Fam Nurs. 2007; 13(2):201-225.

45. Gao X, Sun F, Ko E, Kwak J, Shen HW. Knowledge of advance directive and perceptions of end-of-life care in Chinese-American elders: The role of acculturation. Palliat Support Care. 2015;13(6):1677-1684.

46. Colclough YY, Young HM. Decision making at end of life among Japanese American families. Journal of Family Nursing. 2007;13(2):201225.

47. Hattori K, Ishida DN. Ethnographic study of a good death among elderly Japanese Americans. Nurs Health Sci. 2012;14(4):488-494.

48. Lee MC, Hinderer KA, Alexander CS. What Matters Most at the End-ofLife for Chinese Americans? Gerontol Geriatr Med. 2018;4:2333721418778195

49. Rhee MK, Jang Y. Factors Associated With Designation of a Substitute Decision-Maker in Older Asian Americans: The Role of Cultural Factors. Int $J$ Aging Hum Dev. 2019:91415019848211.

50. Jia Z, Leiter RE, Yeh IM, Tulsky JA, Sanders JJ. Toward Culturally Tailored Advance Care Planning for the Chinese Diaspora: An Integrative Systematic Review. J Palliat Med. 2020;23(12):1662-1677.

51. Hua M, Lu Y, Ma X, Morrison RS, Li G, Wunsch H. Association Between the Implementation of Hospital-Based Palliative Care and Use of Intensive Care During Terminal Hospitalizations. JAMA Netw Open. 2020;3(1):e1918675.

52. Aslakson R, Cheng J, Vollenweider D, Galusca D, Smith TJ, Pronovost PJ. Evidence-based palliative care in the intensive care unit: a systematic review of interventions. J Palliat Med. 2014;17(2):219-235.

53. Temel JS, Greer JA, Muzikansky A, et al. Early palliative care for patients with metastatic non-small-cell lung cancer. $N$ Engl $\mathrm{J}$ Med. 2010;363(8):733-742. 
54. Ferrell BR, Temel JS, Temin S, et al. Integration of Palliative Care Into Standard Oncology Care: American Society of Clinical Oncology Clinical Practice Guideline Update. J Clin Oncol. 2017;35(1):96-112.

55. Milazzo S, Hansen E, Carozza D, Case AA. How Effective Is Palliative Care in Improving Patient Outcomes? Curr Treat Options Oncol. 2020;21(2): 12 .

56. Bell CL, Kuriya M, Fischberg D. Hospice referrals and code status: outcomes of inpatient palliative care consultations among Asian Americans and Pacific Islanders with cancer. $J$ Pain Symptom Manage. 2011;42(4):557-564.

57. La IS, Lee MC, Hinderer KA, et al. Palliative Care for the Asian American Adult Population: A Scoping Review. Am J Hosp Palliat Care. 2020: 1049909120928063.

58. Silva MD, Tsai S, Sobota RM, Abel BT, Reid MC, Adelman RD. Missed Opportunities When Communicating With Limited English-Proficient Patients During End-of-Life Conversations: Insights From SpanishSpeaking and Chinese-Speaking Medical Interpreters. Journal of Pain \& Symptom Management. 2019;25:25.

59. Scholz B, Goncharov L, Emmerich N, et al. Clinicians' accounts of communication with patients in end-of-life care contexts: A systematic review. Patient Educ Couns. 2020
60. Holland AT, Palaniappan LP. Problems with the collection and interpretation of Asian-American health data: omission, aggregation, and extrapolation. Ann Epidemiol. 2012;22(6):397-405.

61. Adia AC, Nazareno J, Operario D, Ponce NA. Health Conditions, Outcomes, and Service Access Among Filipino, Vietnamese, Chinese, Japanese, and Korean Adults in California, 2011-2017. Am J Public Health. 2020;110(4):520-526.

62. Huynh QL, Devos T, Smalarz L. Perpetual Foreigner in One's Own Land: Potential Implications for Identity and Psychological Adjustment. J Soc Clin Psychol. 2011;30(2):133-162.

63. Chen HA, Trinh J, Yang GP. Anti-Asian sentiment in the United States COVID-19 and history. Am J Surg. 2020;220(3):556-557.

64. Teno JM, Gozalo P, Trivedi AN, et al. Site of Death, Place of Care, and Health Care Transitions Among US Medicare Beneficiaries, 2000-2015. JAMA. 2018;320(3):264-271.

Publisher's Note: Springer Nature remains neutral with regard to jurisdictional claims in published maps and institutional affiliations. 